\title{
СОЦИУМ
}

СЕЦКО Александра Александровна,

студентка бакалавриата по направлению подготовки «Политология» Восточного института - Школы региональных и международных исследований ДВФУ (г. Владивосток).

Электронная почта: setcko.aa@students.dvfu.ru

ТАНЦУРА Марина Сергеевна,

канд. полит. наук, доцент кафедры политологии Восточного института - Школы региональных и международных исследований ДВФУ (г. Владивосток).

Электронная почта: tantsura.ms@dvfu.ru

\section{Проблемы цифровой идентичности современной молодёжи на примере студенческого сообщества ДВФУ}

В статье рассматривается развитие информационных технологий и усиление их роли не только в повседневной жизни, но и в сознании людей, особенно молодёжи. Цифровая идентичность вытесняет этническую, религиозную, территориальную обилием информации, свободой действий, обезличенностью и возможностью самореализации. Тем самым происходит снижение заинтересованности людей в реальном общении, в рамках которого приобретаются навыки коммуникации и формируются устойчивые отношения к себе и к миру как основа самоидентификации. В статье анализируются проблемы цифровой идентичности современной молодёжи, а именно процесс накопления цифрового следа, идентификация личности и последствия влияния информации

С каждым годом всё больше людей на планете начинает выходить в сеть с помощью мобильных устройств, доступный интернет меняет их мир: в бизнесе - упрощает коммуникацию и увеличивает продажи, в образовании - обучает знаниям в интересной форме и предоставляет доступ к разнообразным источникам информации, в медицине - контролирует здоровье людей и оптимизирует работу больниц и т. д. Интернет предоставляет огромные возможности для развивающихся стран и создаёт ещё более невероятное для развитых. Он позволяет взаимодействовать гражданам и правительствам на совершенно ином уровне: с одной стороны, мы получаем относительную прозрачность власти; случаи коррупции, нарушений законодательства, вымогательства попадают в сеть, распространяются среди всего населения, что может стать поводом для привлечения фигурантов к ответственности; с другой стороны, тотальный контроль, власть сможет получать ещё больше данных о своих гражданах и использовать в своих целях. Цифровые данные будут работать против самих людей: не то скачал, чтобы обойти цензуру, или не то написал в порыве эмоций, впоследствии может сыграть с человеком злую шутку - увольнение с работы, отказ в получении кредита или ещё хуже - попадание в тюрьму [3, с. 34-36]. виртуальная

идентичность,

интернет-

пространство,

кониепиия симулякров, молодёжь,

соицальные сети,

ииффровая

идентичность,

ичифровой след

Для циитирования:

Сецко А. А., Танцу-

ра М. С. Проблемы цифровой идентичности современной молодёжи на примере студенческого сообщества ДВФУ // Известия Восточного института. 2021. № 1 . C. 29-36. DOI https://doi. org/10.24866/2542-1611/2021$1 / 29-36$ 
От массового доступа в интернет в итоге выиграют все. Те, у кого ничего нет, получат хотя бы что-то, а те, кто имеет многое, будут иметь еще больше. И даже нехорошие репрессивные власти будут в итоге интернетом повержены [3, с. 37]. Благодаря интернету все люди становятся равными: совершенно неважно, где ты родился, какой у тебя пол, во что ты веришь и что ел сегодня на завтрак. В виртуальном мире это всё не имеет никакого значения. Стремительное развитие информационных технологий и массовое внедрение их в повседневную жизнь влечет за собой серьёзные изменения в сознании людей, особенно молодёжи, потому именно она более всего подвержена влиянию информационных технологий. Обилие информации, свобода действий, обезличенность, другими словами, виртуальный мир, в котором можно создавать всё что угодно, привлекает людей и заставляет больше времени проводить в интернет-пространстве. Вследствие чего у индивидов формируется новая структура ценностей.

Важной компонентой ценностей является идентичность, тождественность, динамическая система представлений личности о самой себе, складывающихся в ходе самоопределения индивида и его позиционирования в социуме. С этими представлениями связаны переживания личности. Идентичность может быть интерпретирована как психологическое ядро личности, поскольку она включает в себя самосознание, ценностно-смысловую и регулятивную сферы. Идентичность формируется в процессе реального общения, сравнения себя с другими, осознанного изменения себя в стремлении к идеальной форме - физической, умственной, духовной.

Молодые люди проводят большое количество времени в социальных сетях, где общаются, учатся, взаимодействуют, т.е. виртуально коммуницируют. Чрезмерное погружение в цифровое пространство приводит к снижению заинтересованности людей в реальном общении, в рамках которого приобретаются важные навыки коммуникации и формируются устойчивые отношения: к себе и к миру как основа самоидентификации личности.

Получается, что различные элементы идентичности переносятся из реального мира в виртуальный, формируя тем самым ложный образ Я-концепции. Данный феномен обусловлен отсутствием у человека определённых возможностей для проявления индивидуальности и самореализации в повседневной жизни, что подталкивает индивида к поискам виртуальных компенсаций. Исследователи данного направления характеризуют цифровую идентичности как: «киберидентичность», «сетевая идентичность», «метаидентичность», «репостидентичность», «идентичность в виртуальном пространстве».

Существует множество значений идентичности в информационном пространстве, которые следует различать: виртуальная идентичность [5, с. 112] - составная часть социокультурной идентичности личности, которая относится к осознанию своей принадлежности к определенной (не всегда фиксируемой в реальном социуме) общности, осуществляющей деятельность в информационно-коммуникационных средах. Цифровая идентичность - процесс создания индивидом своей цифровой проекции в сети, который включает в себя весь комплекс данных о человеке в Интернете [4, с. 209].

Интернет - свободное пространство, где нет рамок и границ, контроля и наказаний, предписаний и стандартов, вследствие чего про- 
исходит девальвация традиционных человеческих ценностей, утрата общепринятых моделей поведения, разрушение традиционной идентичности и трансформация личности в виртуальную, вынужденную адаптироваться к обстановке новой информационной реальности и самоидентифицироваться в быстро меняющемся информационном потоке виртуального пространства.

Таким образом, виртуальная и цифровая идентичности в современных реалиях начинают вытеснять этническую, религиозную и даже территориальную своим неограниченным и глобальным характером. Границы доминирования национальных традиционных ценностей, символов и смыслов, транслируемых государством, теряют свою информационную силу, а на смену им приходят альтернативные идеологии, формируемые посредством применения инструментов политической коммуникации другими государствами или транснациональными корпорациями (ТНК). Пользователи интернета начинают идентифицировать себя не с традиционными территориями, а с сетевыми сообществами, в рамках которых они активно коммуницируют друг с другом.

Концепция «Человек мира» становится всё популярнее среди молодого поколения, люди интересуются жизнью других, делятся фотографиями, обсуждают новости, оказывают поддержку, развлекаются, смотрят кино и слушают музыку, они неосознанно перенимают универсальные ценности, смыслы и символы, не придают особого значения месторождению, перестают идентифицировать себя со своим государством. Соответственно, они подвержены большему влиянию виртуальных средств массовой коммуникации, выступающих инструментом реального влияния на политическое пространство с содержательной точки зрения, а в ряде случаев посредством разрушения существующей национальной и территориальной идентичности могут применяться в качестве инструмента изменения реальных государственных границ.

В контексте данного вопроса особое значение получает концепция симулякров Бодрийяра, который утверждает, что сегодня исчезла грань между реальностью и симуляцией. Жизнь предлагает отображение реального намного чаще, чем саму реальность: то, что обозначает нечто, для нас существует; что не имеет обозначения, несущественно, другими словами, Бодрийяр провозглашает универсальность симулякра и исчезновение реального. Согласно исследователю, симуляция $[1$, c. 15] - это совокупность несуществующего на самом деле, но представляющегося реальным, т.е. способ существования современного «виртуализированного» общества.

Таким образом, получается, что в современном обществе знание о реальности заменило саму реальность настолько, что вопрос о соотнесении знака и вещи, истинного и ложного больше не возникает $[1$, c. 16]. Вследствие чего информация, которая попадает в сеть, не проходит проверку на качество, подлинность и авторство, её могут разместить искусственно сконструированные псевдоличности, симулирующие существование реального интернет-пользователя в оффлайновом пространстве, чьи реальные характеристики соответствуют заявленным, и осуществляющие от его лица коммуникацию в интернете, так называемые киберсимулякры [2, с. 17-18]. Цели данных публикаций могут быть различны: от компрометации органов 
власти и разрушения традиционных ценностей - до акцентирования внимания на важных темах и формирования массовых моделей поведения. По состоянию на конец 2013 г. 61,5\% всего трафика в сети генерировалось такими искусственно созданными личностями. С учётом широких возможностей симуляции в интернет-пространстве, они могут обладать практически любыми социокультурными и демографическими характеристиками, что обеспечивает высокую эффективность таргетирования информационно-коммуникационного воздействия применительно к целевым аудиториям политического управления [2, с. 19].

Молодые люди, обсуждая какие-то темы, «репостя» новости, выкладывая публикации со своими рассуждениями, даже не могут себе представить, какое сильное влияние на них оказывают киберсимукляры в интернет-пространстве, как реальные политические процессы уступают место смоделированным виртуальным конструкциям, которые воспринимаются не до конца сформированным сознанием молодёжи в качестве действительности, вызывая соответствующие вполне реальные, в большей степени негативные эмоции, эффекты и последствия.

Способы формирования цифровой идентичности существенно отличаются от той идентичности, которая нам более привычна для понимания: отсутствует влияние со стороны референтных групп, которые склонны навязывать определённые ценности, значимость структуры организации и интеграции поведения в различных областях жизни.

1) Опосредованный характер. Идентичность в виртуальном пространстве проявляется через определённые символы: имя профиля («ник»), фотография («аватарка»), стиль профиля, позиционирование, статус, «посты». Чем больше они отличаются от реального облика человека, тем больше виртуальная идентичность не совпадает с реальной, что формирует ложный образ о человеке среди других пользователей.

2) Анонимность. Индивид как пользователь интернета имеет право скрыть данные о себе и коммуницировать анонимно, т. е. открыто выражать свои эмоции и чувства, высказываться в любой форме, не задумываясь о последствиях. Так как пребывание в виртуальном пространстве не физическое, то оно формирует у человека чувство псевдобезопасности и безнаказанности, что и провоцирует недопустимый стиль коммуникации. Таким образом, анонимность может обусловить появление безосновательного чувства собственного величия и привести к социальному растормаживанию, что существенным образом влияет на формирование идентичности.

3) Ложный характер. Виртуальная реальность позволяет создавать новый мир и, соответственно, новую идентичность, обладающую идеальным набором качеств и характеристик. Данный процесс осуществляется оптимизированно путём подбора заготовленных символов, однако в итоге мы получаем личность, лишённую уникальности. У неё отсутствуют особенные характеристики: внешний облик, знания, навыки, ценности, мировоззрение, из которых впоследствии складывается идентичность.

4) Самопрезентация. Цифровая идентичность не формируется сама по себе, она осознанно компилируется из некоторого набора 
виртуальных инструментов с целью быть презентованной другим пользователям сети. В социальных сетях важными составляющими успеха являются престиж и статус. Они определяются количеством лайков, репостов, комментариев, охватов, чем их больше, тем более популярным становится пользователь и возрастает его престиж.

Для выявления проблемы цифровой идентичности современной молодёжи необходимо определить, как происходит накопление цифрового следа, идентифицируется личность в цифровой среде и какие последствия наступают в реальной и виртуальной жизни индивида.

Наш цифровой след [4, с. 210] состоит из нескольких слоёв:

- первый - информация о себе, которуюе люди самостоятельно публикуют и могут контролировать (информация в профиле, фото- и видеоматериалы, личные переписки, поисковые запросы, «репосты» и публикации);

- второй - информация о поведении в сети, которая создает контекст для цифровой активности и которую невозможно отследить, изменить или удалить (местоположение, проведенное время, психологические особенности);

- третий - интерпретация информации из первого и второго слоя, анализ данных и сравнение с другими пользователями для выявления значимых статистических корреляций (семейное положение, страхи, мечты, обязательства, идеи, образование), чтобы знать всё о людях и правильно преподносить товары и услуги.

Мы провели исследование всех слоёв цифрового следа, опросив студентов ДВФУ по следующим параметрам [платформа: Googleforms, опрошенных: 100, время: неделя]:

1) Информация о себе:

а) Мотивы пребывания в сети:

- коммуникация;

- самовыражение;

- получение информации;

- заработок;

- развлечение;

- образование.

b) Для чего вы идёте в сеть и потребляете контент:

для удовлетворения своих потребностей; для общения.

2) Информация о поведении в сети:

c) Насколько важным является перманентное пребывание в сети и обновление своих данных.

d) Что из выкладываемого контента показывает вашу ориентацию в социуме.

е) Мобильность/включённость как основная ценность.

3) Интерпретация информации:

f) Что для вас является «Своим кругом» Бурдьё: место нахождения или место цифрового присутствия.

g) Насколько транслируемый контент близок вашей системе ориентаций:

- внешность;

- круг интересов;

- социальная среда присутствия;

- политические ориентации. 
h) Насколько совпадает в сети и в реальной жизни референтная и реальная группа.

Таким образом, можно предположить, что процесс цифровой идентификации личности начинает играть всё большую роль в современном мире. Реальный образ Я-концепции неразрывно связан со своим виртуальным продолжением: не только с точки зрения развития науки и техники, увеличения информационных потоков, расширения коммуникационных сетей, стирания социальных и психологических связей, но и с точки зрения предоставления неограниченных возможностей в самовыражении, реализации идей, раскрытии потенциала, невоплотимого в жизни.

В ходе исследования был проведен социологический опрос студентов ДВФУ с целью определения цифровой идентичности, осознания себя и своего места в Интернете и выявления проблем идентификации. По результатам можно сделать следующие выводы:

- более 53\% респондентов идентифицируют себя как «Человек мира», а не гражданин РФ, что демонстрирует влияние процесса глобализации на сознание молодого поколения;

- около $43 \%$ респондентов указали, что им легче самореализовываться и реализовывать свои идеи в Интернет-пространстве, а также одним из самых популярных мотивов пребывания в Сети стало самовыражение - 66\%, что свидетельствует об осознании молодёжи всех возможностей информационных технологий, частичной девальвации традиционных коммуникативных навыков и начала процесса трансформации личности в виртуальную;

- 70\% респондентов подчеркнули значимость проведения времени в Интернете с целью коммуникации, получения информации и развлечения, что демонстрирует привязанность людей к Социальным медиа, но при этом только 40\% важно обновлять свои данные в Сети, что говорит о нейтральном отношении молодого поколения к своей информационной проекции;

- менее $40 \%$ респондентов сомневаются в соответствии транслируемого контента (фото/видео материалы, комментарии, посты) и их реальными интересами, внешними данными, положением в обществе, что объясняет влияние приложений, искажающих фото, цитирование чужих мыслей и желание казаться тем, кем не являются на самом деле;

- более 60\% отметили, что в Интернет-пространстве есть люди, чьё мнение для них важно. Студенты активно следят за их жизнью, смотрят видеоролики, читают посты и разделяют взгляды лидеров по многим вопросам. Такие результаты демонстрируют, что большая часть опрошенной молодёжи способна оказаться под влиянием интернет-личностей, новостного контента, ценностей.

При этом стоит отметить, что молодёжь реже беспокоится о негативных выбросах в Сети - 10\%, чаще предпочитает личные встречи $83 \%$ и старается проверять информацию в Интернете - 47\%. Таким образом, есть доля студентов, которые задумываются о последствиях, осознанно подходят к делу и критически мыслят.

Таким образом, исследование показало, что проблема цифровой идентичности среди молодёжи действительно существует. Какие будут последствия в будущем, предположить сложно, но уже сейчас можно сказать, что если люди не начнут меньше времени проводить 
в Интернете, анализировать происходящие вокруг процессы, пытаться самореализоваться в реальном мире, то человечество может столкнуться с кризисом традиционных ценностей, а воздействие искусственного интеллекта помимо множества положительных факторов принесёт опасность подмены понятий.

\section{Литература}

1. Бронзино Л. Ю. Концепция симулякров Жана Бодрийяра: методология «Алеаторного мышления» и «Трансформация субъекта в обществе потребления» // Вестник российского университета дружбы народов. Серия: Социология. 2011. № 1. С. 11-23.

2. Володенков С. В. Интернет-технологии как современный инструмент виртуализации массовой политической реальности // Вестник московского университета. Серия 12: Политические науки. 2017. № 2. C. 15-23.

3. Коэн Д., Шмидт Э. Новый цифровой мир. Как технологии меняют жизнь людей, модели бизнеса и понятие государств / пер. с англ. С. Филина. М.: Манн, Иванов и

Фербер, 2013. - 367 c.

4. Кондаков А. М., Костылева А. А. Цифровая идентичность, цифровая самоидентификация, цифровой профиль: постановка проблемы // Вестник российского университета дружбы народов. Серия: Информатизация образования. 2019. № 3. C. 207-218.

5. Солдатова Е. А., Погорелов Д. Н. Феномен виртуальной идентичности: современное состояние проблемы // Образование и наука. 2018. № 5. С. 105-124.

6. Соловьева Л. Н. Цифровая идентичность как новый вид идентичности человека информационной эпохи // Общество, философия, история, культура. 2018. № 12 (56). C. 40-43.

\section{Alexandra A. SETSKO}

Undergraduate Student in the field of political science, Oriental Institute - School of Regional and International Studies, Far Eastern Federal University (Vladivostok, Russia)

E-mail: setcko.aa@students.dvfu.ru

\section{Marina S. TANTSURA}

Ph. D. (in Political Science), Associate Professor, Department of Political Science, Oriental Institute - School of Regional and International Studies, Far Eastern Federal University (Vladivostok, Russia)

E-mail: tantsura.ms.@dvfu.ru

\section{Problems of digital identity of modern youth on the example of the FEFU student community}

The article considers the development of information virtual identity, technologies and the strengthening of their role not only in Internet space, everyday life, but also in the minds of people, especially young simulacrum concept, individuals, as not fully formed personalities. The author emphasizes that digital identity replaces ethnic, religious, and territorial identity with an abundance of information, freedom of action, depersonalization, and the possibility of self- digital identity, realization. Thus, there is a decrease in people's interest in real digital footprint communication, in which important communication skills are acquired and stable attitudes towards themselves and the world are formed as the basis of self-identification. The article also 
analyzes the problems of modern society, where knowledge about reality has replaced reality itself so much that the boundaries between true and false are blurred, and the problems of digital identity of modern youth, namely the process of accumulating a digital footprint, personal identification, and the consequences of the influence of information.

For citation: Setsko A. A.,Tantsura M. S. Problems of digital identity of modern youth on the example of the FEFU student community // Oriental Institute Journal. 2021. № 1. P. 29-36. DOI https://doi.org/10.24866/25421611/2021-1/29-36

\section{References}

1. Bronzino L. Yu. Kontseptsiya simulyakrov ZHana Bodrijyara: metodologiya «Aleatornogo myshleniya» $\mathrm{i}$ «Transformatsiya sub"ekta v obshhestve potrebleniya» // Vestnik rossijskogo universiteta druzhby narodov. Seriya: Sotsiologiya. 2011. № 1. S. 11-23.

2. Volodenkov S. V. Internet-tekhnologii kak sovremennyj instrument virtualizatsii massovoj politicheskoj real'nosti // Vestnik moskovskogo universiteta. Seriya 12: Politicheskie nauki. 2017. № 2. S. 15-23.

3. Koehn D., SHmidt EH. Novyj tsifrovoj mir. Kak tekhnologii menyayut zhizn' lyudej, modeli biznesa i ponyatie gosudarstv / per. s angl. S. Filina. M.: Mann, Ivanov i Ferber, 2013. - 367 s.
4. Kondakov A. M., Kostyleva A. A. TSifrovaya identichnost', tsifrovaya samoidentifikatsiya, tsifrovoj profil': postanovka problemy // Vestnik rossijskogo universiteta druzhby narodov. Seriya: Informatizatsiya obrazovaniya. 2019. № 3 . S. $207-218$.

5. Soldatova E. A., Pogorelov D. N. Fenomen virtual'noj identichnosti: sovremennoe sostoyanie problemy // Obrazovanie i nauka. 2018. № 5. S. 105-124.

6. Solov'eva L. N.

TSifrovaya identichnost' kak novyj vid identichnosti cheloveka informatsionnoj ehpokhi // Obshhestvo, filosofiya, istoriya, kul'tura. 2018. № 12 (56). S. 40-43 